\title{
Aspectos da identidade docente de professores dạs séries inicciais do Ensino Fundamental e sua influência no Ensino de ciências
}

\author{
The teaching of science and the identity of primary school teachers
}

\author{
Marco Aurélio Alvarenga Monteiro ${ }^{* 1}$ e Isabel Cristina de Castro Monteiro ${ }^{2}$
}

${ }^{1}$ Doutor, docente da Universidade Estadual Paulista Júlio de Mesquita Filho e do Programa de Pós-Graduação em Educação para a Ciência - UNESP/Bauru, SP, Brasil.

${ }^{2}$ Doutor, docente da Universidade Estadual Paulista Júlio de Mesquita Filho, atuando no Departamento de Física e Química- FEG- UNESP e credenciada no Programa de Pós-Graduação em Educação para a Ciência- PGFC- FC-

UNESP- Bauru, SP, Brasil.

\begin{abstract}
Resumo
Este trabalho foi realizado com objetivo de estudar as variáveis que interferem na autonomia de professoras das séries iniciais em seus esforços por construir um ensino de Ciências mais significativo para seus alunos. Nossa investigação direcionou especial atenção sobre a identidade docente e como ela reage aos processos que visam o estabelecimento de uma prática pedagógica inovadora e autônoma. Analisamos a narração de memórias das experiências com o ensino de Ciências de três professoras das séries iniciais que, no contexto de um curso de formação continuada de professores, planejavam mudanças no ensino de Ciências que ministravam para seus alunos. Como resultado, observamos a maneira como a história de formação e de exercício profissional interfere decisivamente na identidade docente e em suas concepções sobre autonomia profissional.
\end{abstract}

Palavras-chave:Identidade docente, formação de professores, autonomia do professor, ensino de ciências.

\begin{abstract}
This paper was conducted to study the variables that interfere in the autonomy of the primary school teachers in their efforts to build a more meaningful Science education for their students. Special attention was directed for research on teacher identity and how it reacts to the proceedings for the establishment of an innovative and autonomous pedagogical practice. Was analyzed the narratives regarding educational experiences and memories of a group of the three primary school teachers, in the context of a course of continuous training of teachers. As a result we see how the story of training and professional practice can interfere decisively in the teacher identity and in the his conceptions on professional autonomy.
\end{abstract}

Keywords: Teacher identity, teacher training, teacher autonomy, science teaching. 


\section{Introdução}

$\mathrm{O}$ $\mathrm{s}$ tempos atuais, denominados por alguns como a sociedade pós-moderna e por outros como era da informação, têm sido marcado por intensas dúvidas e contradições, haja vista a constante quebra de paradigmas e o consequente caráter provisório do conhecimento. Assim, o constante bombardeio de informações a que somos expostos em nosso cotidiano define a influência esmagadora da mídia sobre nossas vidas, ditando uma miríade de diferentes valores e regras que nos alienam e passam a conduzir nossos gostos, preferências, desejos, sonhos e crenças (KENSKI, 1994).

Em nome de uma regra mercadológica, própria de uma ideologia comercial e consumista, somos violentados em nossa identidade, ou seja, vamos nos conformando a uma certa lógica e assumindo determinadas práticas que nos são impostas sem, muitas vezes, termos a oportunidade de reflexão e autonomia. Nessa direção, o conhecimento passa a desempenhar um papel preponderante nessa nova sociedade - tanto do ponto de vista da sobrevivência do próprio mercado, quanto da defesa de nossa identidade - que busca se proteger dos processos de descaracterização e alienação a que está constantemente submetida. Do ponto de vista do mercado, o conhecimento se destaca como fator decisivo para os processos de produção, já que, segundo suas próprias regras, inovação e criatividade são elementos fundamentais para a competitividade. Com relação à preservação de nossa identidade, o conhecimento se mostra ainda mais necessário, pois exige muito mais do que a simples obtenção de informações (MONTEIRO, 2006).

Para Morin (2000) é preciso transformar as informações em conhecimento pertinente. Assim, é necessário o desenvolvimento do pensamento no sentido de que, além de tratar as informações de maneira adequada, buscando identificá-las e relativizá-las num certo contexto, também seja capaz de analisá-las quanto às consequências de suas aplicações na sociedade.

Paralelo a isso, surgem questionamentos sobre o papel do professor nessa sociedade da informação, na qual meios mais rápidos e eficientes são propostos como substitutos legítimos de sua função. Assim como muitas profissões sucumbiram com o desenvolvimento científico e tecnológico, pode o professor ser substituído pelas novas mídias educacionais?

Para Nóvoa (2002), mesmo com o grande desenvolvimento tecnológico dos meios de informação, o professor ainda desempenha papel importante na era da informação:

É verdade que hoje o conhecimento se encontra disponível numa diversidade de formas e lugares. Mas o momento do ensino é fundamental para o explicar, para revelar sua evolução histórica e para preparar a sua apreensão crítica (NÓVOA, 2002, p. 252).
Da mesma forma, Pimenta (2000) coloca-se de forma contrária à corrente de desvalorização profissional do professor, bem com as concepções que o consideram um técnico reprodutor de conhecimentos. Contudo, para a autora, é preciso considerar que a profissão professor, como qualquer outra, surge em dado contexto histórico em função das necessidades da sociedade. Assim, à medida que a sociedade se transforma algumas profissões desaparecem, outras surgem, enquanto outras sofrem mudanças, adquirindo novas características que atendam às novas demandas da sociedade. Este é o caso da profissão de professor.

Dessa maneira, há que se considerar o caráter dinâmico da docência como prática social e a urgência de se estabelecer as novas especificidades da identidade desse profissional. Para tanto, é preciso responder: que professor se faz necessário para atender às necessidades dos cidadãos da sociedade contemporânea? Em que consiste a identidade docente dos dias atuais?

O conceito de identidade profissional do professor tem se destacado como fator importante nas pesquisas educacionais, pois caracteriza as diferentes maneiras de cada profissional ser e se sentir professor. Nóvoa (1998) afirma que toda profissão define uma identidade que é construída num processo de socialização. Para o autor, a identidade não é algo adquirido e definido, como se fosse uma propriedade; ela se constitui num processo de construção, no qual as lutas e os conflitos próprios da prática profissional definem sua maneira de atuar.

Para Hall (1999), a concepção de identidade desenvolveu-se desde a postura do sujeito do Iluminismo, evoluindo para a ideia do sujeito sociológico, até atingir o conceito de sujeito pós-moderno. Na concepção do Iluminismo, o sujeito era visto como indivíduo, único, centrado, possuidor das capacidades de consciência e razão. Nessa concepção a essência do verdadeiro "eu" consistia na sua identidade. Essa visão extremamente individualista, solipsista, foi superada e substituída pela concepção sociológica. O sujeito passaria a ser visto como um amálgama de diferentes "eus", produto das múltiplas interações do sujeito com a sociedade. O sujeito ainda tem um núcleo ou essência interior que é o "eu real", que não está isolado e nem é inato; portanto, é estruturado e modificado num processo interacionista contínuo com a cultura e as demais identidades que os cercam. Assim, a identidade se constitui no elo que une o sujeito à cultura e aos demais sujeitos que convivem com ele, tornando-os estáveis e previsíveis. $\mathrm{Na}$ pós-modernidade, surge um sujeito fragmentado, sem identidade fixa permanente. Nessa concepção, o sujeito assume diferentes identidades que não se estruturam em torno de um "eu" coerente.

O argumento principal nessa visão é o de que existem diferentes identidades conflitantes e contraditórias em nós, deslocando constantemente nossa identificação. Assim, a ideia de uma identidade plenamente caracterizada 
e estável é uma ilusão. Laclau (1990) usa o conceito de "deslocamento" para explicar essa instabilidade. Para o autor, o deslocamento da identidade central, sem que nenhuma outra assuma essa função, não significa a inexistência de centro, ao contrário determina múltiplos centros, aos quais ele denominou de "pluralidade de centros de poder".

As sociedades pós-modernas, vistas segundo esse referencial, podem ser consideradas como desprovidas de um centro organizador que determinam ocorrências sem uma "Lei" ou "Causa" únicas. Em constante conflito com as diferentes identidades que se deslocam exercendo diferentes forças, atuantes em diferentes direções, essas sociedades não entram em colapso por apresentarem certa articulação que, apesar de parcial, pois a estrutura identitária continua sempre aberta, define um vínculo estrutural (HALL, 1999).

Para o autor, o que se tem sido chamado de crise de identidade é a ação conjunta de um duplo deslocamento, a descentralização dos indivíduos tanto do seu lugar no mundo social e cultural quanto de si mesmos. Assim, a identidade não é um dado imutável que, conferido ao indivíduo no início da vida, se mantém constante e inalterada, ao contrário, se constitui num processo dinâmico de socialização.

Esse processo de socialização pode ser explicado pela teoria do interacionismo simbólico proposto por Mead (1934). Segundo essa teoria, a interação é o elemento constituinte das formas de comportamento. A natureza do mundo é social e simbólica; assim, o ser humano é sujeito e agente, pois interpreta e simboliza. O self, ou seja, a identidade pessoal, muda continuamente desde o nascimento e durante todas as experiências vividas pelo sujeito. Essas constantes mudanças ocorrem na direção de um ajuste aos processos de interação entre o sujeito e os outros. Nessa perspectiva, cada sujeito estrutura seu self em função das reações e expectativas que o outro apresenta segundo suas interpretações acerca das ações do sujeito no processo interativo. Os comportamentos esperados numa relação social determinam regras e padrões a que todos os membros de uma sociedade precisam respeitar para interagir e viver em coesão. Em outras palavras, nós necessitamos interiorizar o comportamento das pessoas para nos relacionarmos com elas.

Baptista (2002), traçando considerações sobre a compreensão teórica no processo de formação da identidade profissional, cita Berger \& Luckman (1983) para explicar o conceito de socialização primária e secundária. $\mathrm{Na}$ socialização primária, o processo interativo se dá nas relações familiares. Com forte apelo emocional, essa primeira etapa da socialização é marcada pela aquisição da linguagem e pela interiorização de aspectos culturais sem muito controle racional por parte do sujeito. A socialização secundária pode ser entendida como uma interação que se dá nas relações extra-familiares. Nesse processo, o sujeito interage com os denominados "sub-mundos institucionais" que necessitam ser interiorizados. O sujeito, então, introjeta outros papéis sociais, entre os quais o papel profissional, que envolvem desde simples rituais até complexos componentes normativos, cognitivos e afetivos, relativos à questão do trabalho.

Segundo Heller (1992), a profunda interiorização dos papéis sociais por parte de um indivíduo pode, por um lado, permitir uma inserção automática do indivíduo na realidade, entretanto também pode moldar de tal maneira o sujeito, que o impede de construir uma personalidade mais autônoma. A essa incapacidade criativa e imóvel do sujeito, caracterizada por uma "mesmice", denomina-se identidade do mito. Por outro lado, se, durante a socialização secundária, o processo de interiorização ocorrer num movimento dialético, de forma que o sujeito possa vivenciar vários papéis, essas diferentes percepções podem permitir a construção de uma identidade com maior autonomia em relação aos modelos oferecidos, denominada de identidade autônoma.

Desse modo, os processos de construção da identidade, do mito ou autônoma, são relativos às condições tanto objetivas, como a estrutura social, os grupos de referência, instituições, etc., quanto subjetivas, representadas pela capacidade e oportunidade de reflexão de cada um dos sujeitos pertencentes do grupo social. Assim, nossa auto-identidade é fortemente influenciada pelo que pensamos sobre o que o outro pensa sobre nós, ou seja, é só na relação com o outro que pode ocorrer a complementaridade (HABERMAS, 1990). Porém, esta complementaridade nem sempre é genuína, ela pode ser negativa, no sentido da anulação do eu em função do outro, ou seja, o outro impõe uma identidade indesejada.

O conceito de "identidade coletiva" proposto por Habermas (1990), no qual os indivíduos pertencentes a um determinado grupo social passam a adotar papéis, normas e valores válidos para todos os componentes do grupo, reafirmando constantemente uma realidade objetiva e subjetiva, define com sucesso uma socialização secundária. Caso contrário, se no grupo existirem representantes que apresentam divergências, rupturas, inconsistências ou diferenças profundas, pode haver impossibilidade de efetivação da socialização secundária.

Diante dessas considerações podemos admitir que a identidade profissional do professor se estabelece num processo de socialização secundária que ocorre num determinado contexto histórico, tendo em vista que sua construção ocorre a partir de uma significação social da profissão em resposta a uma necessidade da sociedade. Além disso, é preciso considerar a significação pessPortanto, os professores, mediante um processo de interação com seus pares, regras institucionais e expectativas sociais em torno do seu exercício profissional, vão adquirindo valores, atitudes, interesses, destrezas e conhecimentos que se refletem em suas ações e fazeres pedagógicos. Nessa mesma direção, Pimenta (2000) afirma: 
Uma identidade profissional se constrói, pois, a partir da significação social da profissão; da revisão constante dos signos sociais da profissão; da revisão das tradições. Mas também da reafirmação de práticas consagradas culturalmente e que permanecem significativas. Práticas que resistem as inovações porque prenhes de saberes válidos às necessidades da realidade. Do confronto entre as teorias e as práticas, da análise sistemática das práticas à luz das teorias existentes, da construção de novas teorias. Constróise também pelo significado que cada professor, enquanto ator e autor, confere à atividade docente no seu cotidiano com base em seus valores, em seu modo de situar-se no mundo, em sua história de vida, em suas representações, em seus saberes, em suas angústias e anseios, do sentido que tem sua vida o ser professor. Assim como a partir de sua rede de relações com os outros professores nas escolas, nos sindicatos e em outros agrupamentos (PIMENTA, 2000, p. 19).

Em resumo, durante sua trajetória profissional, o professor constrói sua identidade docente influenciado por pelo menos dois grandes processos de interação:

- $\quad$ socialização primária, na qual valores e personalidade se fundamentam nas relações familiares.

- socialização secundária, que se desmembra em duas grandes vertentes. A primeira, na direção da adaptação ao grupo do qual faz parte; a segunda, nas regras normativas e institucionalizadas pelas leis e decretos que regulamentam o ensino no País.

Nesse sentido, Dubar (1997) evidencia que as identidades humana e profissional do professor são forjadas numa complexidade tal que as mudanças sociais influenciam significativamente sua prática pedagógica em sala de aula. Dessa maneira, nem sempre consciente dos processos que vão conformando sua maneira de ser e agir, o professor vai construindo, ao longo de suas experiências com o ensino um saber docente que se inicia em seus primeiros contatos com a escola, como aluno do Ensino Fundamental, passando pelas etapas relativas aos cursos de sua formação profissional inicial, para ganhar contornos mais nítidos nas muitas e variadas vivências que o exercício de seu ofício lhe proporciona. Assim, cada professor tem sua história, e cada história tem muitos professores, professoras, amigos, diretores, livros, atividades, avaliações, alunos, alunas sucessos, derrotas, alegrias, inseguranças, frustrações, conflitos, desencontros, encontros, etc. Cada história conta outras histórias, e elas ficam arquivadas nas memórias de cada docente, não apenas como lembrança de tempos que não voltam mais, mas como indicadores que atuam inconscientemente, condicionando hábitos, definindo atitudes e determinando ideias, convicções, modos de agir e seu saber pedagógico (MONTEIRO \& TEIXEIRA, 2004).

Por isso, ser professor na sociedade complexa atual não é tarefa fácil. Conviver com os múltiplos conflitos provenientes de diferentes interesses dos muitos grupos sociais que, de uma forma direta ou indireta, atuam sobre a escola, geram problemas extrínsecos ao trabalho docente os quais afetam drasticamente a realidade de sala de aula.

Essa multiplicidade de conflitos no contexto escolar tem contribuído para a efetivação do que muitos têm chamado de crise de identidade do professor. Assim, as constantes mudanças nas regras institucionais que são impostas ao professor de forma acrítica, bem como o seu isolamento na solidão de sala de aula, tem propiciado a construção de uma identidade do mito. Além disso, é preciso considerar que as intensas mudanças de escola às quais o professor deve submeter-se - e, portanto, aos constantes processos de socialização e re-socialização com novos grupos, o que dificulta a construção de uma identidade coletiva - aliadas aos inúmeros cursos de atualização profissional que não levam em conta as especificidades da identidade de cada professor e da realidade que vive em suas escolas, geram a insegurança e a imobilidade profissional dificultando uma atuação mais coerente e ajustada às novas exigências sociais.

Portanto a crise de identidade do professor é gerada por instabilidades nos paradigmas que definem o caráter dessa profissão, tendo em vista as dificuldades intensas que o professor encontra na socialização em seu meio profissional.

Não se pode acreditar que, por receberem um mesmo rótulo profissional: ser professor, possamos desconsiderar as especificidades das diferentes trajetórias que esses profissionais percorreram para construir suas identidades como docentes. Mesmo que essas trajetórias tenham sido semelhantes, cada qual interagiu de maneira diferente com as experiências que vivenciou, mesmo porque cada qual teve uma socialização primária particular e única. Em resumo, não se pode dissociar a identidade profissional e a identidade pessoal do professor, uma vez que isso tem impacto decisivo em sala de aula, pois cada qual tem seus valores, sentimentos, convicções e crenças que o levam a praticar a docência de maneira diversa de seus pares.

Assim, ao nosso ver, mais do que uma crise de identidade docente, há uma crise de identidade na escola, pois cada profissional tende a deslocar os objetivos educacionais para um determinado interesse e compreensão da realidade. Dessa forma, temos conflitos insuperáveis que se refletem na má qualidade do ensino e na, consequente, má formação de nossas crianças e jovens. Isso se torna ainda mais grave no Ensino Fundamental, não apenas por ser o ensino básico que vai socializar a criança com o ambiente escolar e definir, de certa forma, a relação dela com o ensino formal, mas por causa da estrutura em ciclos, adotada por muitas redes de ensino, que exige uma unidade de objetivos e um trabalho didático-pedagógico coletivo.

Nesse nosso trabalho, buscamos investigar a identidade de três professoras das séries iniciais do Ensino Fundamental, a partir da narração de memórias que elas fazem em relação as experiências que tiverem com 
o ensino de Ciências, em especial ao ensino de Física. De posse desses dados, procuramos analisar como que aspectos dessa identidade docente interferem na maneira com essas professoras organizam seu fazer pedagógico e como resistem às propostas que visam implementar a pesquisa e a inovação em suas aulas de ciências, relativos aos conteúdos de Física.

\section{A pesquisa}

Nossa pesquisa estabeleceu-se no contexto de uma escola pública municipal de séries iniciais do Ensino Fundamental numa cidade do interior de São Paulo. Ela desenvolveu-se mediante um curso de formação continuada que oferecemos a 22 professoras. Contudo, os dados obtidos para nossa pesquisa foram coletados num estudo com 03 professoras que ministravam aulas para crianças de faixa etária compreendida entre 07 e 10 anos.

O trabalho com essas três professoras deveu-se ao fato de serem as únicas docentes que se disponibilizaram de livre e espontânea vontade a participarem de nossa pesquisa.

Essas professoras possuem, além de larga experiência docente, mais de 15 anos de serviço, formação superior, sendo formadas pelo Programa "PEC - Formação Universitária".

Para caracterizarmos aspectos da identidade docente das professoras, registramos em vídeo as narrações de memórias feitas por elas, a partir de suas lembranças relacionadas com o ensino de Ciências, em especial ao ensino de Física, que tiveram, na condição de alunas e que ministraram, na condição de docentes.

Nossa intenção foi resgatar autobiografias visando identificar origens de certas posturas no modo de trabalhar, de encarar determinadas dificuldades, de resistir ou assimilar mais facilmente determinados referenciais teóricos etc.

Como afirma Kenski (1994), existem vários tipos de estudos que envolvem a memória coletiva seja dos professores de uma escola ou de um grupo que ministra determinada disciplina. Assim sendo, a partir de uma narração individual, oral ou escrita, estabelecem-se as biografias socializadas em que se tem a oportunidade de discutir, analisar e aprimorar pontos comuns e as especificidades da prática docente de cada um.

Optamos, portanto, pela narração oral das professoras acerca de suas lembranças na presença das demais, potencializando os reconhecimentos de vivências comuns, de histórias de vida e profissional semelhantes, de compromissos e ideais próximos, que, de maneira explícita ou implícita, influenciam determinantemente a prática pedagógica de cada uma delas.

A análise dos dados foi feita mediante as indicações de Heller (1992) sobre o conceito de identidade do MITO, que se refere à identidade caracterizada por uma inserção automática do indivíduo na realidade, moldando-o de tal a maneira a impedir de que ele assuma uma postura mais autônoma. As ações do sujeito com identidade do MITO são marcadas por uma incapacidade criativa que leva o sujeito a uma "mesmice". Outro conceito que utilizaremos para caracterização da identidade docente das professoras é o de identidade COLETIVA, proposta por Habermas (1990). Esse tipo de identidade é própria de um processo de socialização secundária que, ao contrário da identidade do MITO, se dá mediante um processo dialético, de forma que o sujeito tem a oportunidade de vivenciar diferentes papéis, tornando-o mais sensível às percepções do outro. Dessa forma, os indivíduos, pertencentes a um determinado grupo social, passam a adotar papéis, normas e valores válidos para todos os componentes do grupo, definindo uma formação capaz de torná-los mais capazes para superar divergências, rupturas e crises.

Além desses dois conceitos, adotaremos as ideias proposta por Hall (1999) em torno da concepção de identidade em CRISE. Esse tipo de identidade pode ser caracterizado quando há uma dificuldade do indivíduo em determinar a si próprio, seus valores, ideias, sentimentos, assim como sua posição social e cultural.

Nesse sentido, procuraremos caracterizar as identidades docentes a partir da fala das professoras que participaram de nossa pesquisa, buscando uma categorização de excertos que tipificam os modelos de identidades destacadas por Hall (opus cit.)

\section{Resultados e Análise dos dados}

As três professoras que participaram de nossa pesquisa serão identificadas pelas iniciais de seus nomes: MENA, DEN e LIS. Alguns trechos considerados mais significativos para nossa análise serão transcritos. Para facilitar o processo de narração de memórias fizemos os alguns questionamentos, de forma que cada professora os utilizasse como roteiro para a narração de suas memórias: Como você se via como aluna? Como seus professores e colegas a viam como aluna? Como você e seus colegas viam seu professor de Física? E agora, enquanto professora, ao se lembrar de você como aluna, qual seria a opinião da professora sobre a aluna? E agora, ao contrário, enquanto aluna daquela época, se tivesse uma professora como você é hoje, como a aluna veria a professora? E como avalia o professor de Física que teve? Como gostaria que seus alunos a vissem? Como foi sua opção pelo magistério? Como avalia sua formação? E os cursos de formação continuada que fez? Como foi sua carreira no magistério até aqui? Como foi enfrentar uma sala de aula pela primeira vez? Qual (is) dificuldade(s) você enfrentou durante sua carreira que já conseguiu superar e qual(is) você ainda não superou? Você tem autonomia profissional?

Apesar da existência do roteiro, alertamos as professo- 
ras de que tais questões não constituíam um questionário que deveria ser rigidamente respondido, mas configurava-se como um guia mediante o qual, no exercício do resgate de suas memórias, se fizesse um recorte de suas lembranças mais pertinentes aos objetivos do trabalho que estávamos iniciando.

A seguir destacamos alguns trechos das narrativas de cada uma das três professoras que, ao nosso ver, revelam esses elementos:

MENA: (...) De Física não me lembro muito bem não! Só sei que eram difíceis. Hoje não me lembro de nada daqueles conteúdos, e acho que é porque aquilo tudo não seria ensinado para as crianças mesmo (...)/ (...) quando a gente tem que escolher os livros que a gente vai utilizar com as crianças, aqueles que têm conteúdos de Física eu não escolho. Não é que eu não acho importante é que eu não tenho segurança para trabalhar com esses conteúdos. Então, eu dou preferência àqueles assuntos que a gente domina mais(...)/Eu não gosto muito de fazer experiências. Dá muito trabalho. Não por causa da preparação, porque apesar de ter quase 20 anos de magistério eu ainda preparo minhas aulas. $O$ problema é a indisciplina! Está muito difícil! Se a gente não tiver jogo de cintura, não dá conta mesmo! Então, fazer experiência dá muita confusão, os alunos ficam muito agitados com novidade e depois para organizá-los de novo é bem difícil. Por isso as aulas precisam ser arroz com feijão mesmo (...)

DEN: (...) As minhas aulas de Física na escola não foram boas. Eram poucas as aulas, todo ano mudava o professor e, eram muito difíceis, sem muita relação com nossa realidade. Eu sempre fui uma boa aluna e sempre tirava boas notas. Na época eu me lembro que perguntava muito. Chegava em casa e treinava bastante. Mas hoje eu não me lembro mais das coisas que eu aprendi. Tinha aquelas palavras difíceis, as fórmulas complicadas... O que mais? Acho que é só o que eu lembro. Os professores não eram ruins não! Era matéria mesmo que é difícil. O que se vai fazer? Física é fogo, não é? Química e matemática também! Se eles tivessem laboratório... Mas eu era persistente e aprendia (...)/ (...)Eu procuro ensinar os conteúdos de Ciências que têm nos livros. A parte de Física, os detalhes, a gente não fala, porque a gente não sabe muito e também não adianta porque se eu falar aquelas palavras difíceis para os alunos eles também não vão entender. É difícil de explicar. As escolas em que eu trabalhei não tinham laboratórios e, então, eu não aprendi a dar aulas com experiências. Nem como aluna. Eu não estudei em nenhuma escola que tivesse laboratório (...)/ (...)-Mas eu acho que seria legal dar aulas de experiência. Seria outra coisa!(...)/ (...) O mundo está cada vez mais moderno e quem não souber Física e as Ciências vai ficar para trás. Fico imaginando a gente chegando com as coisas para fazer experiência na sala!(...)

LIS: (...) de Física eu não sei nada! O professor que eu tive no magistério até era legal, mas não deu para ensinar tudo! Ele até tentou ser sedutor! [Risos]. Eram aulas animadas, mas foi muito pouco. Nós éramos reunidas em grupo e tínhamos que apresentar uma experiência para ele no fim do bimestre para ficar com nota. Os grupos apresentavam as experiências nas aulas e ele fala porque que as coisas aconteciam daquele jeito. Acho isso legal, mas parece que isso é pouco. Quando vi uma colega enfiar um ovo na garrafa! [Risos]. Me lembro que isso foi legal, mas hoje parece que os alunos não se contentam com isso! Fiz isso uma vez, tive o maior trabalho e os alunos não deram muita importância. Sabe? É só na hora e pronto, depois eles já esqueceram, não sabem explicar mais nada. Então eu desisti(...)/ (...)De Ciências eu ensino aquilo que é previsto: o movimento da Terra, falo dos planetas, etc. Falo da pressão do ar, mas sem muitos detalhes. Só o básico. Se eu der para os meus alunos as aulas que eu tive..., Nossa!!!! Nem dá para imaginar! Uma porção de palavras difíceis no meio. Então, eu dou o ponto, explico. Canto música. Trago livros da minha casa para eles pesquisarem. Nada muito interessante (...)/ (...) Eu não faço experiência. Não tem laboratório aqui e, mesmo se tivesse, eu não saberia utilizar(...)/ (...) Assim, eu não faço experiência por opção. Eu não faço porque eu não sei, porque eu não tenho (...)

É possível notar a importância e o destaque que as professoras atribuem às atividades experimentais. Em seus comentários elas enfatizam o aspecto já destacado em muitas pesquisas da área (LABURÚ, 2006; ZANON e SILVA, 2000; ARRUDA e LABURÚ, 1996): a crença dos professores de que a existência do laboratório ou das atividades experimentais podem resolver os problemas de ensino e de aprendizagem em Ciências, bem como as dificuldades que enfrentam em implementarem tais atividades no contexto de sala de aula tendo em vista os problemas de infraestrutura das escolas.

É interessante perceber que ao mesmo que tempo que atribuem grande importância à experimentação, também revelam suas frustrações em suas tentativas de desenvolverem essas atividades com seus alunos.

Mesmo reconhecendo a importância das atividades experimentais no ensino e no aprendizado de Ciências essas evidências nos alertam para o fato de que cursos que buscam, apenas, oferecer às professoras sugestões de práticas experimentais para que se incorporem aos seus fazeres docentes não terão o impacto esperado na melhora do processo de ensino e de aprendizagem.

Muito provavelmente, alguns professores mais idealistas utilizariam a proposta por algum tempo, esforçando-se para superar as múltiplas dificuldades que lhe seriam impostas, tendo em vista a realidade da maioria de nossas escolas (desprovidas de laboratórios, de equipamentos e de tempo para os professores montarem e desmontarem os experimentos em função da alta carga horária a que são submetidos), porém, sem alteração do significado que atribuem ao ensino de Ciências, e ao real papel das atividades experimentais em sala de aula, os resultados, provavelmente, seriam frustrantes e, em pouco tempo, as atividades seriam abandonadas, como destacado por Monteiro (2006).

O desafio se afigurava como a necessidade de mostrar para as professoras que independentemente dos recursos a serem utilizados em sala de aula era fundamental haver 
uma mudança em suas concepções acerca do ensino de Ciências e, consequentemente, na prática pedagógica que estabeleciam em sala de aula.

Nas tabelas a seguir, apresentamos a caracterização que fizemos da identidade docente em função da fala das professoras:

A partir das falas de MENA pode-se perceber a ênfase que ela dá à questão da afetividade no processo de ensino e de aprendizagem. Isso parece causar uma contrariedade entre ela e as demais professoras que já não atribuem tamanha importância a esse aspecto. Talvez essa característica de Mena seja resultado do processo de socialização primária e secundária por qual passou no âmbito de sua família e no início da carreira profissional. Isso nos pareceu evidente numa de suas falas sobre sua carreira profissional:

(...) conversando um dia com ex-colegas de escola, fiquei sabendo que na Diretoria de Ensino de Guaru- lhos havia uma vaga para professora primária e elas já estavam trabalhando por lá. Fui com medo e bastante insegura, pois nunca havia me separado da família ou viajado sozinha (...)/ (...)Nesta escola encontrei pessoas maravilhosas e atenciosas, que me fizeram sentir em ambiente acolhedor, aliviando a saudade que sentia de minha família(...)/ (...) Acho que os meus professores gostavam de mim como aluna, pois apesar de não ser uma aluna de dez, eu sempre obedeci, fui educada, nunca retruquei e nem mesmo era indisciplinada em sala de aula. Se eu fosse minha aluna gostaria de mim!(...)/ (...) Tive excelentes professoras, mas os alunos não davam o menor valor a eles! Me lembro da Dona Ritinha. Quando passou aquela professora mais velhinha no vídeo, logo veio a imagem dela na minha cabeça. Com era boa aquela mulher! Era como uma segunda mãe. Carinhosa, pacienciosa. Era uma artista!

Com relação às suas concepções de autonomia pro-

TABELA 1 - Caracterização da identidade docente da professora MENA

\begin{tabular}{|c|c|c|}
\hline \multicolumn{3}{|c|}{ PROFESSORA MENA } \\
\hline $\begin{array}{c}\text { CONCEPÇÃO DO } \\
\text { EXERCÍCIO DA DOCÊNCIA }\end{array}$ & $\begin{array}{l}\text { CONCEPÇÃO DE } \\
\text { AUTONOMIA }\end{array}$ & FALAS DA PROFESSORA \\
\hline $\begin{array}{l}\text { Explicar para os alunos os } \\
\text { conteúdos. } \\
\text { Manter a disciplina. } \\
\text { Dar carinho aos alunos. } \\
\text { Rigidez de valores e princípios. }\end{array}$ & $\begin{array}{l}\text { Capacidade de atuar } \\
\text { por si só em sala de aula } \\
\text { independente do auxílio de } \\
\text { outra professora. } \\
\text { Atributo que se só se } \\
\text { alcança com a experiência. }\end{array}$ & $\begin{array}{l}\text { “(...) Essa minha maneira (carinhosa com os alunos) de ser sempre } \\
\text { funcionou bem. As crianças aprendiam, eram disciplinadas e meu } \\
\text { trabalho era sempre elogiado por pais, professores e diretores...” } \\
\text { “(...) Ás vezes eu chego a estar com três crianças dependuradas em } \\
\text { mim de uma vez só! Têm gente (refere-se às demais professoras) - } \\
\text { que reclama disso. Dizem que eu deixo as crianças mal-acostumadas. } \\
\text { Mas eu acho isso muito importante ...” } \\
\text { “(...) Para mim, os meus alunos são quase como filhos meus. Eu dou } \\
\text { carinho mesmo. Acho isso muito importante, apesar de ser muito } \\
\text { criticada pelas colegas eu nem ligo, porque são crianças, precisam } \\
\text { disso. A gente que é adulto precisa, imagine elas”. } \\
\text { “(...) Eu não gosto muito de fazer experiências. Dá muito trabalho. } \\
\text { Não por causa da preparação, porque apesar de ter quase } 20 \text { anos } \\
\text { de magistério eu ainda preparo minhas aulas. O problema é a } \\
\text { indisciplina! Está muito difícil! Se a gente não tiver jogo de cintura, } \\
\text { não dá conta mesmo! Então, fazer experiência dá muita confusão, os } \\
\text { alunos ficam muito agitados com novidade e depois para organizá- } \\
\text { los de novo é bem difícil. Por isso as aulas precisam ser arroz com } \\
\text { feijão mesmo...” } \\
\text { “(...) É claro que eu ensino também, mas essas crianças precisam mais } \\
\text { de carinho, afeto e atenção..." } \\
\text { “(...) Quanto a ter autonomia eu tenho um pouco. No início de } \\
\text { carreira não! Eu dependia muito das colegas (...) com o passar do } \\
\text { tempo e fui ficando mais independente e rapidinho eu já fazia tudo } \\
\text { sozinha...” “(..) Hoje, por causa dessa minha maneira de ser mais } \\
\text { carinhosa com as crianças meu trabalho tem sido mais diferenciado. } \\
\text { Estou pronta para passar para outras colegas mais novas essa minha } \\
\text { experiência, mas hoje, eu não sei as professoras chegam achando que } \\
\text { sabem tudo, que já se formam com autonomia para fazerem como } \\
\text { bem querem. Só que esquecem que o ser humano não é só cabeça e } \\
\text { cérebro tem as emoções, os sentimentos. Isso é o mais importante. } \\
\text { Depois, chegam no colegial batendo em professor, indisciplinados, } \\
\text { usando droga. O que é isso? Falta de carinho e afeto na infância. }\end{array}$ \\
\hline
\end{tabular}


fissional, Mena apresenta uma visão solipsista, fato que gera uma limitação de sua atuação docente no que diz respeito à criatividade no trabalho em sala de aula. Portanto, entendemos que MENA apresenta uma identidade docente marcada por uma certa rigidez de valores e princípios o que a torna extremamente insegura para alterar seu fazer pedagógico. É possível notar em sua fala que ela afirma "Essa minha maneira de ser sempre funcionou bem". Em outro momento ela destaca: “(...) Por isso as aulas precisam ser arroz com feijão mesmo..." Esse aspecto da identidade docente que evidencia uma certa imobilidade criativa e ações definidas por uma "mesmice", independe da realidade na qual se encontra, caracteriza o que Heller (1992) definiu como IDENTIDADE MITO.

LIS, em diversos momentos de sua fala, evidencia o que Hall (1999) chama de crise de identidade. Apesar de apresentar uma história voltada para um ensino tradicional, LIS sente-se em conflito com as cobranças por uma prática docente que contemple uma participação mais ativa dos alunos no processo de ensino e de aprendizagem. Nesse aspecto há um deslocamento da identidade central estabelecida na prática tradicional de ensino para um outro centro de poder que a faz adotar um discurso mais moderno na qual o professor busca inovações para o seu trabalho. Contudo, como destaca Hall (opus cit) esse deslocamento identitário não anula a identidade anterior, criando conflitos constantes entre os diferentes centros de poder. Essa crise faz com que LIS adote uma postura pendular, ora alinhada com posturas inovadoras, ora assume uma atitude mais conservadora e tradicional. Como sua concepção de autonomia está centrada na ideia de possuir um método na qual, uma vez aplicado, supere os problemas que enfrenta, ela espera encontrá-lo externamente: em cursos, palestras, revistas, etc. Portanto, parece sempre pronta a novas propostas e ideias. Essa postura mostra LIS como uma professora com facilidade para o estabelecimento de uma identidade coletiva, na qual Habermas (1990) estabelece como sendo a adoção de valores e normas e a incorporação de papéis por parte de um grupo de indivíduos pertencentes ao mesmo grupo social. Contudo, esse posicionamento não é o resultado de um processo consciente e reflexivo, mas resultado da crise identitária que não oferece estabilidade.

DEN evidencia em sua fala uma socialização secundária marcada por uma inserção automática na realidade do trabalho docente.

É preciso destacar que quando ela diz: “(...) É para fazer isso eu faço. É para fazer aquilo, faço também..." é possível inferir uma postura de aceitação às condições impostas ao desenvolvimento de seu trabalho.

Essa tendência se reforça quando ela cita o livro didático: “(...) Eu procuro ensinar os conteúdos de Ciências que têm nos livros...".

O processo de interiorização dos papéis que deveria desempenhar se deu de maneira mecânica e sem a existência de um movimento dialético. Como destaca Heller (1992), podemos caracterizar a identidade docente de DEN como a tipo mito, tendo em vista que sua iniciação profissional é marcada quase que por um certo condicionamento social, na qual, seu compromisso profissional não vai além de cumprir procedimentos que lhe são determinados e impostos. Diante de tal realidade, não se sente responsável pelos problemas enfrentados já que cumpre seu papel e faz a parte que lhe cabe. Assim como LIS, DEN aparenta, a princípio, possuir uma identidade

TABELA 2 - Caracterização da identidade docente da professora LIS

\begin{tabular}{|c|c|c|}
\hline \multicolumn{3}{|c|}{ PROFESSORA LIS } \\
\hline $\begin{array}{c}\text { CONCEPÇÃO DO } \\
\text { EXERCÍCIO DA DOCÊNCIA }\end{array}$ & $\begin{array}{l}\text { CONCEPÇÃO DE } \\
\text { AUTONOMIA }\end{array}$ & FALAS DA PROFESSORA \\
\hline $\begin{array}{l}\text { Seguir um método que } \\
\text { realmente ensine os alunos. } \\
\text { Motivar os alunos em classe. } \\
\text { Cumprir o programa previsto. }\end{array}$ & $\begin{array}{l}\text { Saber fazer o trabalho em sala } \\
\text { de aula. } \\
\text { Dominar métodos de ensino. } \\
\text { Conhecer mais sobre o conteúdo } \\
\text { previsto. } \\
\text { Ter meios (laboratório e material } \\
\text { didático) para desenvolver seu } \\
\text { trabalho em sala de aula. } \\
\text { Capacidade que se consegue } \\
\text { por meios externos ao trabalho } \\
\text { docente. }\end{array}$ & $\begin{array}{l}\text { “(...) É injusto! Tive aula num modelo e agora tenho que se ensinar } \\
\text { em outro. Vou em todas às OT(s) (cursos oferecidos pela oficina } \\
\text { pedagógica). Lá, somos cobrados incessantemente para sermos } \\
\text { sedutoras em nossas aulas, tornando os alunos mais envolvidos } \\
\text { em nossas aulas. Entretanto, quando perguntamos como fazer } \\
\text { isso, recebemos como resposta que não há uma receita pronta } \\
\text { [Risos]. Como fazer então?...” } \\
\text { “(...) acho que autonomia a gente nunca pode dizer que tem } \\
\text { totalmente. A gente nunca sabe tudo. Acho que tem coisas que eu } \\
\text { ainda preciso aprender mais. Por exemplo, fazer experiência: não } \\
\text { é fácil para mim. [Risos] } \\
\text { “(...) Fiz isso uma vez (experiências), tive o maior trabalho e } \\
\text { os alunos não deram muita importância. Sabe? É só na hora e } \\
\text { pronto, depois eles já esqueceram, não sabem explicar mais nada. } \\
\text { Então eu desisti..." } \\
\text { “(...) De Ciências eu ensino aquilo que é previsto...” } \\
\text { "(...) Minha expectativa é a de que você possa oferecer para nós os } \\
\text { laboratórios, as experiências, os meios que transformem nossas } \\
\text { aulas...” }\end{array}$ \\
\hline
\end{tabular}


TABELA 3 - Caracterização da identidade docente da professora DEN

\begin{tabular}{|c|c|c|}
\hline \multicolumn{3}{|c|}{ PROFESSORA DEN } \\
\hline $\begin{array}{c}\text { CONCEPÇÃO DO } \\
\text { EXERCÍCIO DA DOCÊNCIA }\end{array}$ & $\begin{array}{l}\text { CONCEPÇÃO DE } \\
\text { AUTONOMIA }\end{array}$ & FALAS DA PROFESSORA \\
\hline $\begin{array}{l}\text { Adaptar-se à escola na qual se } \\
\text { trabalha sem questionamento. } \\
\text { Depende da capacidade do } \\
\text { aluno em aprender. } \\
\text { Cumprir o conteúdo proposto } \\
\text { pelo livro didático. }\end{array}$ & $\begin{array}{l}\text { Independência para agir e fazer seu } \\
\text { trabalho em sala de aula. } \\
\text { Atributo que se conquista com a } \\
\text { experiência. } \\
\text { Controle sobre questões políticas da } \\
\text { carreira profissional. }\end{array}$ & $\begin{array}{l}\text { “(...) Sou profissional e, portanto, me adapto às características da } \\
\text { escola em que eu trabalho. É para fazer isso eu faço. É para fazer } \\
\text { aquilo, faço também...” } \\
\text { “(...) Se os alunos são bons, mais espertos, eu puxo pelo conteúdo. } \\
\text { Mas, se os alunos são mais fraquinhos, com mais dificuldades para } \\
\text { aprender, com muita defasagem, então a gente não pode ir para } \\
\text { frente, não é?...” } \\
\text { “(...) Eu procuro ensinar os conteúdos de Ciências que têm nos } \\
\text { livros...” } \\
\text { “(...) a autonomia a gente ganha com o tempo, com a experiência. } \\
\text { No início a gente não sabe fazer tudo, depende muito dos outros. } \\
\text { Com o tempo a gente já não precisa mais, faz sozinha.” } \\
\text { “(...) ensinar a gente tenta e faz com o que tem. A gente faz como } \\
\text { reza a cartilha, não tem como nadar contra a maré: porque fazer } \\
\text { de um jeito se está todo mundo fazendo de outro? É dar murro em } \\
\text { ponta de faca (...)”. } \\
\text { “(...) Mas eu acho que autonomia é isso. No início eu seguia } \\
\text { exatamente o que as pessoas me diziam para seguir porque eu não } \\
\text { tinha nenhuma experiência, eu não sabia enfrentar uma sala. Agora } \\
\text { a gente já tem um repertório maior..." } \\
\text { “(...) O que eu acho também, da minha autonomia, é que tem coisas } \\
\text { que a gente não domina. Tratam a gente como se fosse qualquer } \\
\text { um, como foi o caso da municipalização. Às vezes a gente está } \\
\text { acostumada com uma escola, uma clientela e, de repente, tem que } \\
\text { mudar, às vezes fica até sem classe. Isso eu acho que é falta de } \\
\text { autonomia...” }\end{array}$ \\
\hline
\end{tabular}

profissional que Habermas (1990) denominou de coletiva. Isso porque aparenta adotar as normas e os valores válidos pelos demais membros da comunidade escolar da qual pertence. Contudo, essa postura é aparente, tendo em vista que sua atitude profissional não reflete suas crenças que se estabeleceram em função da convicção baseada na prática profissional. Como tende a cumprir um procedimento (A gente faz como reza a cartilha, não tem como nadar contra a maré: porque fazer de um jeito se está todo mundo fazendo de outro? É dar murro em ponta de faca (...)" , não se compromete com ele, não se responsabiliza por ele e nem mesmo com seus resultados. Sua concepção de autonomia é centrada em seu fazer em sala de aula, apesar de relacioná-la também com ideia de um certo controle sobre sua carreira profissional.

Enfim, podemos perceber a influência da história de vida e profissional de cada professora em suas identidades docentes e, ao mesmo tempo, identificar como isso se reflete em suas práticas pedagógicas em sala de aula.

Assim sendo, parece-nos importante que esses aspectos sejam levados em conta em processos de planejamento de cursos de formação continuada de professores tendo em vista o fato de que o sucesso de qualquer proposta educacional dependerá fundamentalmente do professor, afinal, em última análise, é ele quem estará, de fato, desenvolvendo a prática de ensino em sala de aula com seus alunos.

\section{Considerações finais}

Este trabalho, portanto, buscou, primeiramente, referenciais teóricos que nos oferecessem meios para compreender os processos que interferem e determinam a formação da identidade docente. Nossa preocupação era entender como ocorre o desenvolvimento de habilidades e competências que determinam a identidade autônoma ou não de cada professor.

Autores como Laclau (1990), Habermas (1990), Heller (1992), Hall (1999) e Baptista (2002) evidenciam o processo de socialização como mecanismo fundamental para a formação e estruturação da identidade.

Nesse sentido, não é a experiência que determina a forma de ser professor, sua capacidade, sua competência profissional, mas a maneira pela qual essa experiência se estabeleceu e foi refletida, compreendida.

Sob o estado ilusório de que a autonomia se estabelece em situações nas quais sozinho define e determina suas 
ações, o professor é conformado a processos de socialização profissional caracterizados por "fazeres" e "saberes" que não passam por uma análise crítica que possibilita adaptações, generalizações ou aperfeiçoamentos.

Essa foi a realidade que detectamos em nossa investigação. As professoras evidenciavam concepções solipsistas de autonomia e, apesar de se dizerem possuidoras de uma autonomia parcial, competência que, segundo elas, só foi conquistada com o tempo de serviço, deixavam transparecer, em suas narrativas, que, apesar de dominadas, do ponto de vista do "saber fazer" (tendo em vista a experiência profissional) não possuíam uma consciência do "por que fazer". Isso ficou claro quando foi citada a busca que empreendem por uma "receita pronta" de como ensinar Ciências, sem saberem definir os objetivos ou mesmo os conteúdos da disciplina.

Porém, apesar dessa dependência inconsciente das professoras, o fato delas se colocarem à disposição para procurarem o curso de formação continuada e dentre 22 profissionais se disponibilizarem a participarem desse estudo, ao nosso ver, revela algo positivo: ao perceberem suas dependências, relativas às limitações de seus conhecimentos, tomaram a atitude de ampliá-los. Isso é o primeiro passo para tomarem consciência das necessidades de seus alunos, das características de seus pares, das idiossincrasias da instituição da qual fazem parte, da comunidade na qual a escola está inserida, entre outras.

Enquanto buscam uma "receita de como ensinar", reconhecem sua limitação relativa ao conhecimento científico que vai ensinar, aos meios didáticos que pode utilizar, e, portanto, parecem estar conscientes de sua dependência do livro didático, ou de sugestões externas que as orientem em seus trabalhos.

Dessa forma, a dependência quanto aos cursos de formação continuada, às novas propostas ou estratégias inovadoras para o ensino não é o que se deseja superar, tendo em vista que a dependência da atualização de conhecimentos é realidade de qualquer profissão, entretanto é fundamental que o professor possa estar consciente de que essas estratégias ou propostas precisam ser adaptadas às características do contexto escolar no qual desenvolve seu trabalho.

\section{Referências}

ARRUDA, S. M \& LABURÚ, C. E. Considerações sobre a função do experimento no ensino de ciências. In: Pesquisas em ensino de ciências e matemática. Série: Ciências \& Educação, n. 3, Bauru, São Paulo, 1996. p.14-24.

BAPTISTA, M.T.D.S. O estudo de identidades individuais e coletivas na constituição da história da psicologia. Memorandum, Belo Horizonte, 12 de nov. 2002. Disponível em: http://www.fafich.ufmg. br/ memorandum/artigos02/baptista01.html. Acesso em: Acesso em 11 de jul. 2014.

BERGER, P \& LUCKMANN, Th. A construção social da realidade. 5 ed. Petrópolis: Vozes. 1983

DUBAR, C. A Socialização: Construção das Identidades Sociais e profissionais. Porto: Porto Editora. 1997.

HABERMAS, J. Para a reconstrução do materialismo histórico. 2 ed. São Paulo: Brasiliense. 1990

HALL, S. Identidade cultural na pós-modernidade. 8a ed. São Paulo: DP\&A. 1999

HELLER, A. O cotidiano e a história. 4a ed. Rio de Janeiro: Paz e terra, 1992

KENSKI, V. M. Memória e ensino. Cadernos de pesquisa, n.90. São Paulo: Cortez editora, 1994.

LABURÚ, C. E. Fundamentos para um experimento cativante. Caderno Brasileiro de Ensino de Física ,v. 23, n. 3, dezembro de 2006.

LACLAU, E. New Reflections on the Resolution of our Time. Londres: Verso, 1990.

MEAD, G. Mind Self and Society from the Standpoint of a Social Behaviorist. Chicago: University of Chicago, 1934.

MORIN, E. A cabeça bem-feita. Repensar a Reforma, Reformar o Pensamento. Rio de Janeiro: Bertrand Brasil, 2000.

MONTEIRO, M.A.A.; TEIXEIRA, O.P.B. O ensino de Física nas séries iniciais do Ensino Fundamental: um estudo das influencias das experiências docentes em sua prática em sala de aula. Investigações em Ensino de Ciências. V(9), n. 1, pp. 7-25, 2004. Disponível em: http://www.if.ufrgs.br/ienci/artigos/Artigo ID108/ v9 n1 a2004.pdf. Acesso em 11 de julho de 2014.

MONTEIRO, M.A.A. Um estudo da autonomia docente no contexto do ensino de ciências nas séries iniciais do ensino fundamental. 2006. 305 f. Tese (Doutorado em Educação para a Ciência). Faculdade de Ciências, UNESP, Bauru, 2006.

NÓVOA, A. As ciências da educação e os processos de mudanças. In: PIMENTA, S. G. Pedagogia, ciência da educação. São Paulo, Cortez, 1998.

NÓVOA, A. O espaço público da educação: imagens, narrativas e dilemas. In: PROST, A. et.al. Espaços de Educação. Tempos de Formação. Lisboa: Fundação Calouste Gulbenkian, 2002. 
PIMENTA, S.G. Formação de professores: identidade e saberes da docência. In: PIMENTA, S.G. (org). Saberes pedagógicos e atividade docente. São Paulo, Cortez, 2000 .

ZANON, Lenir B.; SILVA, Lenice H. A. A Experimentação no Ensino de Ciências. In: SCHNETZLER, R. P.; ARAGÃO, R. M. R. de. Ensino de Ciências: fundamentos e abordagens. Campinas: Capes/Unimep, p. 120-153, 2000. 